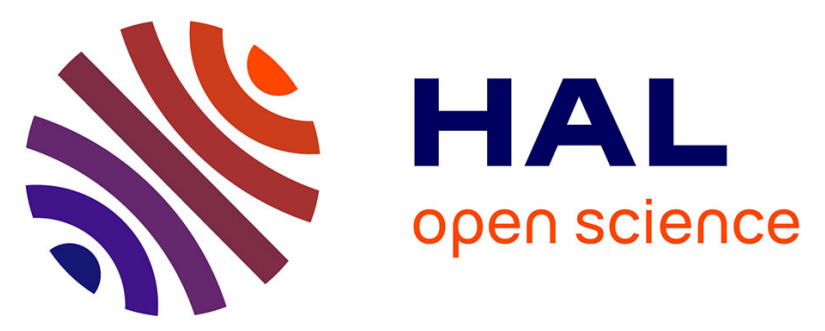

\title{
Manganese Mapping Using a Fluorescent Mn 2+ Sensor and Nanosynchrotron X-ray Fluorescence Reveals the Role of the Golgi Apparatus as a Manganese Storage Site
}

Sayani Das, Asuncion Carmona, Kaustav Khatua, Francesco Porcaro, Andrea Somogyi, Richard Ortega, Ankona Datta

\section{To cite this version:}

Sayani Das, Asuncion Carmona, Kaustav Khatua, Francesco Porcaro, Andrea Somogyi, et al.. Manganese Mapping Using a Fluorescent Mn 2+ Sensor and Nanosynchrotron X-ray Fluorescence Reveals the Role of the Golgi Apparatus as a Manganese Storage Site. Inorganic Chemistry, 2019, 58 (20), pp.13724-13732. 10.1021/acs.inorgchem.9b01389 . hal-02349653

\section{HAL Id: hal-02349653 \\ https://hal.science/hal-02349653}

Submitted on 9 Dec 2020

HAL is a multi-disciplinary open access archive for the deposit and dissemination of scientific research documents, whether they are published or not. The documents may come from teaching and research institutions in France or abroad, or from public or private research centers.
L'archive ouverte pluridisciplinaire HAL, est destinée au dépôt et à la diffusion de documents scientifiques de niveau recherche, publiés ou non, émanant des établissements d'enseignement et de recherche français ou étrangers, des laboratoires publics ou privés. 


\section{Manganese Mapping Using a Fluorescent $\mathrm{Mn}^{2+}$}

\section{Sensor and Nano-SXRF Reveals the Role of}

\section{the Golgi Apparatus as a Manganese Storage}

\section{Site}

Sayani Das, ${ }^{\mathrm{a}}$ Asuncion Carmona, ${ }^{\mathrm{bc}}$ Kaustav Khatua, ${ }^{\mathrm{a} \ddagger}$ Francesco Porcaro, ${ }^{\mathrm{bc}}$ Andrea

Somogyi ${ }^{\mathrm{d}}{ }^{\text {Richard Ortega }}{ }^{\mathrm{bc}}$ and Ankona Datta ${ }^{\mathrm{a}}{ }$

${ }^{\text {a }}$ Department of Chemical Sciences, Tata Institute of Fundamental Research, 1 Homi Bhabha

Road, Colaba, Mumbai-400005, India

${ }^{\mathrm{b}}$ Chemical Imaging and Speciation, CENBG, University of Bordeaux, UMR 5797, 33175

Gradignan, France

${ }^{\mathrm{c}}$ CNRS, IN2P3, CENBG, UMR 5797, 33175 Gradignan, France

${ }^{d}$ Nanoscopium Synchrotron SOLEIL Saint-Aubin, 91192, Gif-sur-Yvette Cedex, France

$\star$ equal contribution

*ankona@tifr.res.in (corresponding author)

KEYWORDS 
Manganese sensing, Golgi apparatus, fluorescent manganese sensors, synchrotron X-ray fluorescence nano-imaging

\section{ABSTRACT}

Elucidating dynamics in transition metal distribution and localization under physiological and pathophysiological conditions is central to our understanding of metal ion regulation. In this forum article, we focus on manganese and specifically recent developments that point to the relevance of the Golgi apparatus in manganese detoxification when this essential metal ion is over-accumulated either due to environmental exposure or mutations in manganese efflux transporters. In order to further evaluate the role of the Golgi apparatus as a manganese ion storage compartment under sub-cytotoxic Mn levels, we use a combination of confocal microscopy using a sensitive 'turn-on' fluorescent manganese sensor and nano-synchrotron Xray fluorescence imaging to show that manganese ions are also stored in the Golgi under physiological conditions. Our results along with previous reports on manganese accumulation now imply a central role of the Golgi apparatus in manganese storage and trafficking under subcytotoxic Mn levels.

\section{INTRODUCTION}

The interplay between metal ion compartmentalization and dynamics has emerged as a prominent concept in investigations into the regulatory and signaling roles of transition metal ions. ${ }^{1-3}$ Existing challenges in metallo-biology are related to addressing critical questions in metal ion homeostasis some of which include: How are correct metal ions installed in protein active sites? ${ }^{4}$ How do biological systems regulate metal ion mobilization in response to external conditions? ${ }^{1}$ Can we identify threshold levels for competing pathways of metal ion channeling 
especially what concentrations trigger pathological pathways? ${ }^{5,6}$ Which pathways are vulnerable to pathogens and how do pathogens hack the cellular metal ion inventory? ${ }^{7,8}$ Multiple recent reports have tried to answer these questions. ${ }^{1-3}$ Results from these studies highlight the ability of biological systems to optimally use compartmentalization and dynamically re-purpose compartments in response to external and internal stimuli. ${ }^{1-3}$ In this context, strategic combination of molecular biology tools, chemical probes, and metal ion imaging techniques have led to the discovery of new transporters, compartments, and pathways in metal ion homeostasis. Further, these efforts have brought forth previously unanticipated roles of transition metal ions like copper, iron, and manganese in biological decision making and defense processes. ${ }^{9-15}$

Manganese has recently been in the focus due to reports on novel roles of the labile manganese pool and identification of manganese specific transporters. ${ }^{9,} 16-20$ In 2004, Daly and coworkers provided evidence that related the high-radiation resistance of bacteria like Deinococcus radiodurans to $\mathrm{Mn}^{2+}$ accumulation in this species in a concentration dependent manner. ${ }^{16}$ The result led to a series of studies aimed toward identifying the $\mathrm{Mn}^{2+}$ species responsible for radiation resistance. These studies revealed the importance of low molecular weight labile $\mathrm{Mn}^{2+}$ species in conferring radiation resistance and opened up the hypothesis that labile $\mathrm{Mn}^{2+}$ species might act as anti-oxidants. ${ }^{16}$ While the superoxide dismutase activity of labile $\mathrm{Mn}^{2+}$ had been proposed earlier, Valentine and coworkers showed in 2012 that labile $\mathrm{Mn}^{2+}$ complexes could catalyze superoxide dismutation under physiological concentrations. ${ }^{21}$ These series of studies pointed to a significant biological role of the labile $\mathrm{Mn}^{2+}$ pool other than providing metal ions for protein-binding. At about the same time, in 2012, a $\mathrm{Zn}^{2+}$ transporter, $\mathrm{ZnT10}$, was reclassified as an exclusive $\mathrm{Mn}^{2+}$ transporter, SLC30A10. ${ }^{22}$ A set of $\mathrm{Mn}^{2+}$ transporters which included SLC30A14, SLC39A14 and SLC39A8 were also identified. ${ }^{19,23-26}$ Further, between 2009 and 2016, multiple studies by Tuschl and co-workers showed that mutations in the transporters, 
SLC39A14 and SLC30A10, led to manganese induced Parkinsonism in young adults and children. $^{19,22,27-29}$ The past two decades have been extremely prolific with studies on Mn, identifying new roles of the labile $\mathrm{Mn}^{2+}$ pool both in physiological and pathophysiological states. Importantly, these studies have led to a niche area in Mn biology which is directly trying to address $\mathrm{Mn}^{2+}$ localization and dynamics along with the localization of $\mathrm{Mn}^{2+}$ transporters in the context of these new discoveries.

The identification of intra-cellular locations of $\mathrm{Mn}^{2+}$ pools initially relied on experiments involving uptake of ${ }^{54} \mathrm{Mn}^{2+}$ and organelle isolation to determine the extent of uptake within an organelle under a specific condition. ${ }^{30}$ Mukhopadhyay and Linstedt showed in 2011 that the introduction of a gain-of-function mutation in SPCA1 which is a Golgi localized $\mathrm{Mn}^{2+}$ influx transporter increased $\mathrm{Mn}^{2+}$ levels in the Golgi and protected cells against $\mathrm{Mn}^{2+}$ toxicity. ${ }^{30}$ Importantly, cells expressing the mutant SPCA1 transporter showed $70 \%$ increased cell viability upon exposure to $\mathrm{mM}$ levels of $\mathrm{Mn}^{2+}$ when compared to wild-type cells indicating a plausible detoxification role of the Golgi. One of the functions of the Golgi apparatus involves metal ion sequestration into the lumen. ${ }^{31}$ The sequestered metal ions are either channeled into the cytoplasm for metal ion related functions or putatively removed into the extra-cellular space under metal overload conditions. ${ }^{31}$ The localization of Mn within the Golgi under Mn overexposure conditions was also revealed by Carmona and co-workers in $2010{ }^{32}$ Synchrotron X-ray fluorescence (SXRF) nano-imaging was used to generate Mn elemental maps in frozen cells and showed Mn localization in the Golgi apparatus in rat dopaminergic cells. ${ }^{32,} 33$ This result was obtained by developing a correlative microscopy approach combining SXRF imaging and organelle fluorescence microscopy. ${ }^{32,34}$ Following this work, multiple studies on different cell types showed clear $\mathrm{Mn}$ localization in the Golgi apparatus under different $\mathrm{Mn}$ exposure conditions (Table S1, ESI $\dagger$ ). A point to note from these reports was that the cells used for these 
studies which included both neuronal cells and HeLa cells, did not express the $\mathrm{Mn}^{2+}$ efflux transporter SLC30A10. Mutations in this transporter are directly related to childhood onset of manganese induced Parkinsonism. ${ }^{35,36}$ Further, Carmona and co-workers showed that overexpression of SLC30A10 in HeLa cells led to a loss of Mn signal from the Golgi apparatus in SXRF Mn elemental maps. ${ }^{35}$ These results highlighted the relevance of the Golgi apparatus as a compartment for channeling excess Mn under Mn overload and dysregulation conditions. With the identification of the Golgi apparatus as a possible detoxification compartment for excess Mn ions, it becomes imperative to evaluate possibilities of employing imaging techniques that can be applied to living samples, like confocal microscopy in conjunction with $\mathrm{Mn}^{2+}$ selective fluorescent sensors to tease apart the dynamics of the $\mathrm{Mn}^{2+}$ labile pool with respect to the Golgi apparatus. Hence, in this paper we evaluate a sensitive fluorescent $\mathrm{Mn}^{2+}$ sensor for its ability to locate manganese in the Golgi within HEK293T cells under sub-cytotoxic levels of manganese exposure. We compare the results from confocal microscopy using the $\mathrm{Mn}^{2+}$ sensor with nanoSXRF imaging under identical conditions to show that Mn localizes within the Golgi apparatus in these cells under sub-cytotoxic Mn exposure conditions.

\section{EXPERIMENTAL SECTION}

\section{METHODS}

General procedures and materials. Unless otherwise mentioned all chemicals were of analytical grade, obtained from commercial sources, and used without further purification. Dry tetrahydrofuran was obtained by distillation over sodium metal for $1 \mathrm{~h}$. Water used for experiments was deionized using a Milli Q Integral 3 water purification unit (Millipore Corp. Billerica, MA, USA). Silica gel (230-400 mesh size, Merck \& Co., Inc.) and Alumina (Brockmann grade, S D Fine-Chem Ltd.) were used for column chromatography. Solvents used for chromatography were of analytical grade and used without distillation. Eluting systems for 
column chromatography purifications were determined by thin layer chromatography (TLC) analysis. TLC analyses were performed on silica gel $60 \mathrm{~F}_{254}$ (Merck \& Co., Inc.) and aluminium oxide $60 \mathrm{~F}_{254}$ (Merck \& Co., Inc.) TLC plates and the plates were visualized under UV light, 254 $\mathrm{nm}$ and $365 \mathrm{~nm}$. Solvents were evaporated under reduced pressure using a rotary evaporator (BÜCHI Labortechnik AG). Low-resolution mass spectral analyses were carried out with an ESI probe (positive and negative ion modes) on a liquid chromatography mass spectrometer (LCMS2020, Shimadzu Corp.).

Synthesis of the manganese sensor M1. The M1 sensor was synthesized and purified according to a previously reported procedure (general procedures and materials listed in previous section). ${ }^{37}$

Cell culture for confocal imaging. HEK 293T cells were cultured in Dulbecco's Modified

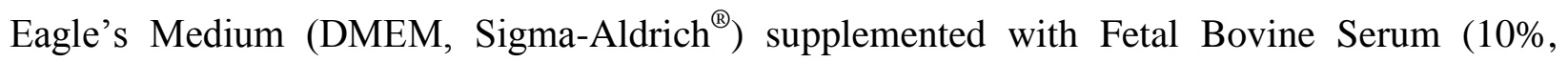
Gibco $\left.^{\circledR}\right)$, Penicillin (50 units/ml, Gibco $\left.{ }^{\circledR}\right)$ and Streptomycin $\left(50 \mu \mathrm{g} / \mathrm{ml}\right.$, Gibco $\left.{ }^{\circledR}\right)$ in T25 culture flasks at $37{ }^{\circ} \mathrm{C}$ under humidified air containing $5 \% \mathrm{CO}_{2}$. A day before the imaging, the cells were plated on glass coverslip bottomed petri plates (35 mm diameter, Tarsons) coated with polylysine $(0.1 \mathrm{mg} / \mathrm{mL})$ and fibronectin $(100 \mu \mathrm{g} / \mathrm{mL})$.

All microscopy experiments were carried out at $25{ }^{\circ} \mathrm{C}$ using an LSM 880 confocal microscope (Zeiss) and images were collected in the internal detector channels using a 40X water immersion objective (Zeiss). Z-series were obtained with a spacing of $0.5 \mu \mathrm{m}$. Modified Thomson's buffer (TB) consisting of sodium HEPES (20 mM), $\mathrm{NaCl}(146 \mathrm{mM}), \mathrm{KCl}(5.4 \mathrm{mM}), \mathrm{MgSO}_{4}(0.8 \mathrm{mM})$, $\mathrm{KH}_{2} \mathrm{PO}_{4}(0.4 \mathrm{mM}), \mathrm{Na}_{2} \mathrm{HPO}_{4}(0.3 \mathrm{mM})$ and glucose $(5.5 \mathrm{mM}) ; \mathrm{pH}$ adjusted to 7.4 was used during the confocal studies. A stock solution of M1 $(705.2 \mu \mathrm{M})$ was prepared in DMSO.

\section{M1 sensor co-localization studies with Golgi Tracker Red}


For the golgi apparatus co-localization studies, HEK293T cells were transduced with CellLight Golgi-RFP (C10593 Molecular probes) by following the protocol provided in the Molecular Probes website. ${ }^{38}$ The CellLight reagent employs BacMam technology to transduce cells with a human Golgi resident enzyme (N-acetylgalactosaminyltransferase) fused to RFP. For Mn treatment, the cells transduced with a CellLight reagent kit were incubated with $25 \mu \mathrm{M}$ and 250 $\mu \mathrm{M} \mathrm{MnCl}_{2}$ in DMEM (free of Phenol Red) for $4 \mathrm{~h}$, washed with TB and further incubated with 5 $\mu \mathrm{M}$ M1 sensor in TB (maintaining $0.7 \%$ DMSO in TB) for 15 min at $37^{\circ} \mathrm{C}$. For experiments on $\mathrm{Mn}^{2+}$ untreated cells an identical protocol was followed excluding the $\mathrm{MnCl}_{2}$ treatment step. Post incubation, the cells were washed multiple times with TB and imaged. Excitation and emission filters were as follows: M1 (ex. 488 nm/em. 495-536 nm), CellLight Golgi-RFP (ex. 543 nm/em. 570-680 nm). Bleed-through experiments were carried out with either the M1 sensor or the Golgi tracker separately under identical experimental conditions and imaging parameters. M1 sensor co-localization imaging data with the Golgi tracker were corrected for bleed-through using the data from the control experiments and applying a linear unmixing algorithm based bleed-through correction available in the confocal imaging software (ZEN 2.3 SP1). For treatment of cells with Tetrakis-(2-pyridylmethyl)ethylenediamine (TPEN), a non-fluorescent divalent metal ion chelator, live HEK293T cells transduced with the Golgi tracker were first incubated with 250 $\mu \mathrm{M} \mathrm{Mn}^{2+}$ in DMEM ( free of Phenol Red) for $4 \mathrm{~h}$, followed by incubation with $\mathrm{M1}$ sensor in TB for $15 \mathrm{~min}$, and then treated with TPEN ( $2 \mathrm{mM}$ in TB) for $10 \mathrm{~min}$, and finally imaged.

All the studies were performed in at least duplicates and the representative images are shown in Figure 1. The confocal image analyses were performed using FIJI (ImageJ, NIH, USA).

Cell culture for SXRF imaging. For synchrotron X-ray fluorescence imaging, cells were cultured directly on sample holders specifically adapted to the synchrotron beamline using 
protocols established at CENBG. ${ }^{39}$ The sample holders made of PEEK had a hole in the middle where a $2 \mu \mathrm{m}$ high grade polycarbonate film was stretched over and glued. The polycarbonate film was treated with gelatine gel ( $2 \%$ in water) to allow cell adhesion. ${ }^{34,35}$ Cells were seeded at low-density 10,000 cell $/ \mathrm{cm}^{2}$. Two days after plating, cells were transduced with CellLight GolgiRFP. Cells were treated with $2 \mu \mathrm{L}$ of BacMam reagent per 10,000 cells for 20 hours. After this time, the medium was removed and cells were exposed for $4 \mathrm{~h}$ at the desired concentration of $\mathrm{MnCl}_{2}(25 \mu \mathrm{M}$ and $250 \mu \mathrm{M})$. Then the culture medium was removed and cells were exposed to $10 \mu \mathrm{g} / \mathrm{mL}$ Hoechst 33342 nuclear dye solution for $15 \mathrm{~min}$ in darkness and at $37{ }^{\circ} \mathrm{C}$. Afterwards, fluorescence images of living cells were acquired using an epifluorescence microscope (Olympus BX51, Tokyo, Japan) and using the set of filters U-MWU2 BP330-385 (Excitation) BA420 (Emission) for blue emission, and U-MWIG2 BP520-550 (Excitation) BA580IF (Emission) for red emission.

After epifluorescence microscopy observation, in order to analyze the constitutive elements of the cells by SXRF, samples must be cryofixed and freeze dried to preserve the cellular structure and elemental content. ${ }^{34,39}$ For this purpose, the samples were quickly washed first with PBS and second with ultrapure water, and rapidly plunge-frozen for $20 \mathrm{sec}$ into isopentane and cooled at $164^{\circ} \mathrm{C}$ with liquid nitrogen. After cryofixation, remaining traces of isopentane were blotted with a paper filter and samples were stored in liquid nitrogen vapors until freeze-drying. SXRF analyses at room temperature are incompatible with the presence of liquid water, so the samples were freeze-dried at $-85{ }^{\circ} \mathrm{C}$ under vacuum $\left(2.5 \times 10^{-3}\right.$ mbar) using Christ alpha $2-4$ LD plus freeze-dryer, for 72 hours.

SXRF imaging. Nano-SXRF imaging was performed at the NANOSCOPIUM beamline ${ }^{40,41}$, Synchrotron SOLEIL, in France. Analyses were conducted at room temperature on cryofixed and 
freeze-dried cells. A $10 \mathrm{keV}$ photon beam was focused at $300 \times 300 \mathrm{~nm}^{2}$ in the sample focal plane with a flux of $10^{10} \mathrm{ph} \cdot \mathrm{s}^{-1}$. Elemental maps were measured by the Flyscan continuous sample scanning technique ${ }^{42}$ with $300 \times 300 \mathrm{~nm}^{2}$ spatial resolution. Full X-ray spectra were detected in each pixel with $300 \mathrm{~ms} /$ pixel exposure time using two Si-SDD detectors located at $120^{\circ}$ respectively to beam direction and at both sides of the sample. Intracellular potassium and chloride was used in SXRF imaging to locate the cell position and hence perform element/organelle correlative imaging.

\section{RESULTS and DISCUSSION}

\section{Investigating intra-cellular $\mathrm{Mn}^{2+}$ localization using a fluorescent $\mathrm{Mn}^{2+}$ sensor}

Metal ion imaging using a selective fluorescent metal ion sensor in a confocal microscopy set-up can provide direct information on intracellular localization of a specific metal ion. 1, 3, 11-13, 43 However, interpretation of imaging data critically depends on prior information on the inherent localization propensities of the sensor. Imaging the sub-cellular localization of $\mathrm{Mn}^{2+}$ using a fluorescent $\mathrm{Mn}^{2+}$ sensor has not been achieved till date, firstly, because of the lack of subcellular organelle targeted $\mathrm{Mn}^{2+}$ sensors. Secondly, there is no clear information on the subcellular targetability of the few existing $\mathrm{Mn}^{2+}$ sensors. The scarcity of fluorescent $\mathrm{Mn}^{2+}$ sensors (add references) which arises from coordination chemistry challenges in developing selective $\mathrm{Mn}^{2+}$ sensors and unavailability of detailed information on their intra-cellular targetability, severely mars the ability to utilize fluorescence microscopy to localize $\mathrm{Mn}^{2+}$ within cells. However, as mentioned in the introduction, recent developments in $\mathrm{Mn}^{2+}$ biology especially related to dynamics in $\mathrm{Mn}^{2+}$ localization under different external and internal conditions necessitate a two-pronged approach: 1 . The development of new organelle targeted $\mathrm{Mn}^{2+}$ sensors and 2. Investigations on existing $\mathrm{Mn}^{2+}$ sensors to check if these sensors can be strategically used 
to gain information on the sub-cellular localization of $\mathrm{Mn}^{2+}$ ions. In this paper we focus on the later approach.
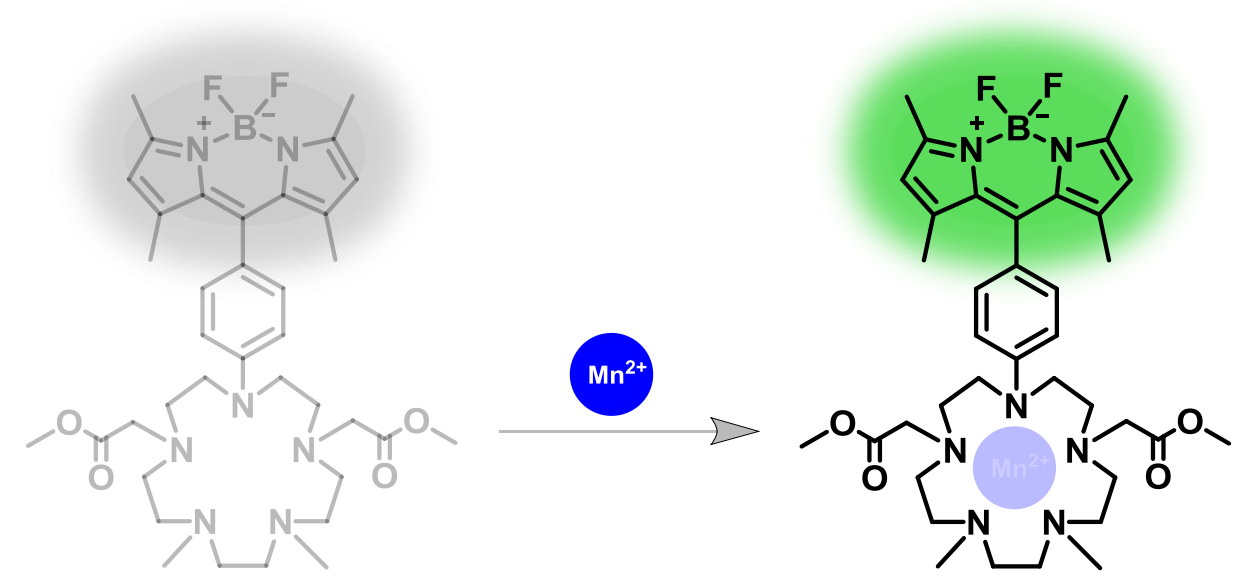

Scheme 1. 'Turn-on' $\mathrm{Mn}^{2+}$ sensor, M1, ${ }^{37}$ used for imaging $\mathrm{Mn}^{2+}$ localization in living cells in this work.

In order to investigate the intracellular $\mathrm{Mn}^{2+}$ localization in live cells, we decided to use an existing fluorescent $\mathrm{Mn}^{2+}$ sensor, M1, that had been previously reported in our laboratory. M1 is a cell-permeable 'turn-on' fluorescent $\mathrm{Mn}^{2+}$ sensor (Scheme 1). ${ }^{37}$ While the sensor has limited aqueous solubility, in an earlier report we had shown the molecule could still be applied successfully for live cell imaging of $\mathrm{Mn}^{2+}$ in HEK293T cells under low levels of sub-cytotoxic $(25 \mu \mathrm{M})$ external $\mathrm{Mn}^{2+}$ exposure by preparing samples in $1 \%$ DMSO in buffer. ${ }^{37}$ The sensor had revealed peri-nuclear punctate staining in cells and we had attributed the punctate staining to the ability of the sensor to localize in lipid rich regions and detect $\mathrm{Mn}^{2+}$ in those compartments. ${ }^{37}$ The ability of the sensor to detect $\mathrm{Mn}^{2+}$ within cells had been confirmed by competition studies with a cell-permeable divalent metal ion chelator. However, we had not further investigated the identity of the compartments in which the sensor was detecting $\mathrm{Mn}^{2+}$ ions. As there has been mounting evidence on the intra-cellular localization of $\mathrm{Mn}^{2+}$ in the Golgi apparatus under $\mathrm{Mn}^{2+}$ 
exposure conditions, and we had earlier observed punctate staining near the peri-nuclear region with our $\mathrm{Mn}^{2+}$ sensor it became necessary to carefully check if a sub-set of the compartments that were showing high fluorescence intensity was the Golgi apparatus and if the sensors could be used to gain further information on $\mathrm{Mn}^{2+}$ localization in living cells.

We therefore used the existing M1 sensor and checked if the fluorescence intensity in HEK293T cells correlated with the location of the Golgi apparatus in these cells. Three sets of experiments were performed on live cells with: 1 . no external $\mathrm{Mn}$ exposure; 2. exposure to $25 \mu \mathrm{M} \mathrm{MnCl}_{2}$; and 3. exposure to $250 \mu \mathrm{M} \mathrm{MnCl}_{2}$. In order to identify which intra-cellular compartments exhibited high fluorescence intensity in the presence of the sensor, the cells were incubated with different organelle trackers that could mark the Golgi apparatus, endosomes, lysosomes, and mitochondria (Figures 1, S1, S2, and S3). As the M1 sensor emitted in the green region of the spectrum $\left(\lambda_{\mathrm{ex}}\right.$ $\left.488 \mathrm{~nm} / \lambda_{\mathrm{em}} 495-536 \mathrm{~nm}\right)$, red-emitting organelle trackers $\left(\lambda_{\mathrm{ex}} 543 \mathrm{~nm} / \lambda_{\mathrm{em}} 570-680 \mathrm{~nm}\right)$ were chosen for the experiments to ensure minimal overlap between the emission of the $\mathrm{Mn}^{2+}$ sensor with that of the organelle trackers. Hence, both Mn untreated and treated HEK293T cells were incubated with the M1 sensor and an organelle tracker and fluorescence images of the cells were recorded on a confocal microscope. In the case of the Golgi tracker a red-fluorescent protein (RFP) tagged marker was transduced into the cells prior to the experiments. The rest of the trackers could be applied via incubation. Importantly, in order to ensure that the co-localization data was interpreted accurately we performed control confocal imaging experiments to check whether there was any fluorescence bleed through from the M1 sensor to the organelle trackers and vice versa. We observed that there was no emission in the green channel when the organelle trackers were excited. However, there was some emission in the red channel for the endosome, lysosome, and Golgi trackers when the M1 sensor was excited. This could be attributed to the tail of the emission spectra of the M1 sensor (Figure S4A) which ranges from $565 \mathrm{~nm}$ to $600 \mathrm{~nm}$. 
Although this would be a minor contribution, we corrected the M1 sensor-organelle colocalization imaging data for bleed through. 


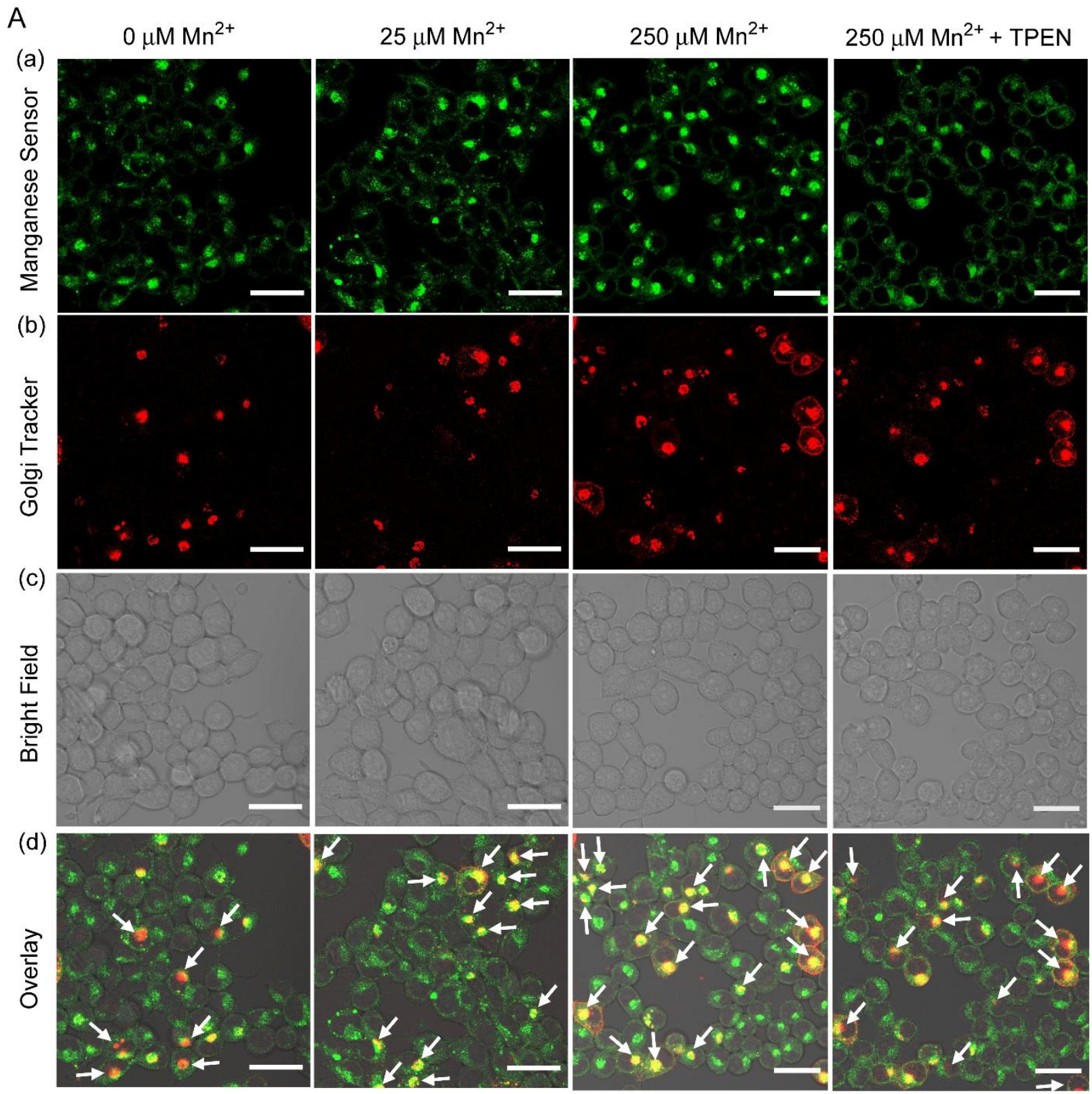

B

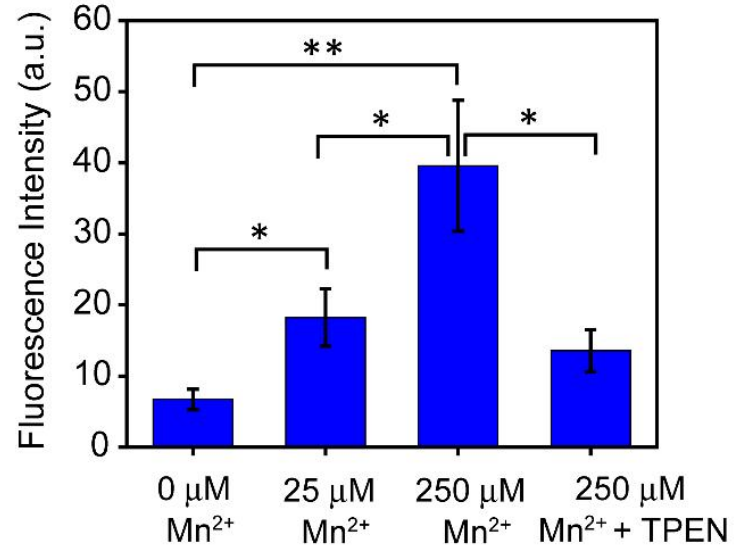


Figure 1. (A) Left to Right, Confocal images of live HEK293T cells with: no external Mn exposure; exposure to $25 \mu \mathrm{M} \mathrm{MnCl}_{2}$; exposure to $250 \mu \mathrm{M} \mathrm{MnCl}_{2}$; exposure to $250 \mu \mathrm{M} \mathrm{MnCl}_{2}$ followed by a cell permeable divalent metal ion chelator tetrakis-(2-pyridylmethyl)ethylenediamine (TPEN). Cells were tranduced with CellLight Golgi-RFP and incubated with $5 \mu \mathrm{M}$ M1. a) M1 sensor emission in green channel, $\lambda_{\text {ex }} 488 \mathrm{~nm}$. b) Golgi-RFP emission in red channel, $\lambda_{\mathrm{ex}}$ $543 \mathrm{~nm}$. Not all cells incorporated the Golgi tracker. c) bright field images. d) bright field images of cells overlaid with confocal images. M1 sensor co-localization imaging data with the Golgi tracker were corrected for bleed-through using the data from the control experiments and applying a linear unmixing algorithm based bleed-through correction available in the confocal imaging software (ZEN 2.3 SP1). White arrows point to representative regions with high intensity in both red and green channels indicating co-localization. Scale bar $=30 \mu \mathrm{m}$. B) Bar plots representing average fluorescence intensities in the green M1 sensor channel obtained from intensity analysis of confocal images shown in panel 1A. For fluorescence quantification, a region of interest (ROI) was created wherever the Golgi tracker was visible. The reported fluorescence intensity was determined by averaging the measured intensity from all ROIs that showed intensity in the red channel. Error bars denote SEM, $n=5$. Statistical analyses performed using an unpaired, two-tailed Student's $t$-test $(* p \leq 0.05, * * p \leq 0.01)$, indicated a significant difference in the intensity between the different sets.

Representative images from the confocal microscopy experiments are shown in Figures 1, S1, and S2. The M1 sensor emission data showed clear perinuclear staining (Figure 1A) that distinctly co-localized with the Golgi tracker (Figure $1 \mathrm{Ab}$ and $1 \mathrm{Ad}$ ) at both $25 \mu \mathrm{M}$ and $250 \mu \mathrm{M}$ $\mathrm{Mn}^{2+}$ exposure levels. In order to compare the localization of the fluorescence intensity from the M1 sensor in $\mathrm{Mn}^{2+}$ treated cells with the localization of the fluorescence intensity from the organelle trackers we performed a line scan within a cell image (Figure S3). We observed clear 
overlap of pixel-wise intensities as shown by correlated increase and decrease in the fluorescence intensities from the M1 sensor and the Golgi apparatus in the $\mathrm{Mn}^{2+}$ treated cells, while the other organelle trackers showed no co-localization with the M1 sensor intensity as shown by the uncorrelated pixel-wise intensities in the line scan (Figure S3). The thresholded Mander's split colocalization coefficients for cells exposed to $250 \mu \mathrm{M} \mathrm{Mn}^{2+}$ were 0.8 and 0.7 for the Golgi tracker and M1 sensor channels, respectively indicating that the M1 sensor fluorescence clearly colocalized with the Golgi tracker. Importantly, intensity for the M1 sensor emission channel was also observed in the perinuclear regions even in cells that had not been externally exposed to $\mathrm{Mn}^{2+}$. Visible inspection of the co-localized images (Figure 1Ad) showed that the intensity of the Golgi tracker remained constant while the intensity of the M1 sensor increased with increasing levels of Mn exposure as indicated by the regions pointed with white arrows which show a progressive color change from orange to yellow. Since $\mathbf{M 1}$ is a 'turn-on' $\mathrm{Mn}^{2+}$ sensor (Figure S4B) this data indicated that $\mathrm{Mn}^{2+}$ ions were present in the Golgi apparatus of HEK293T cells and the concentration $\mathrm{Mn}^{2+}$ ions increased with increasing levels of external $\mathrm{Mn}^{2+}$ exposure.

In order to confirm that the increase in emission of the M1 sensor within the Golgi apparatus was indeed due to the presence of higher levels of $\mathrm{Mn}^{2+}$ in the Golgi apparatus of cells exposed to $\mathrm{Mn}^{2+}$, we performed several control experiments. As M1 is a photo-induced electron transfer based sensor, protonation of the amine group of the dimethylaniline moiety in the sensor scaffold (Scheme 1) might lead to a 'turn-on' response. The $\mathrm{pH}$ of the Golgi apparatus is slightly acidic and is maintained in the $\mathrm{pH}$ range of 6.4 to $6.8 .^{44}$ Hence, it was necessary to check if the fluorescence emission of M1 remained constant within the $\mathrm{pH}$ range of 6.5 to 7.5. The data indicated minimal change in the fluorescence emission of the sensor between $\mathrm{pH} 6.0$ and $\mathrm{pH} 8.0$ (Figure S5). Further, since our sensor had limited water-solubility, we also checked if there was any effect of solvent polarity on the fluorescence emission of the sensor. We observed a 1.6 
times increase in emission intensity for the M1 sensor in ethyl acetate $(\varepsilon=6.02)$ with respect to the fluorescence intensity of the sensor in buffer (Figure S6). A 2.2 times enhancement in was observed when the sensor was dissolved in methanol $(\varepsilon=32.7)$ in comparison to sensor in buffer (Figure S6). For comparison, the dielectric constant of phospholipid membranes is close to 3. (add reference) Therefore we might expect a change in the fluorescence emission of the M1 sensor in lipid rich regions similar to that observed for ethyl acetate. However, in comparison to the fluorescence intensity increase that was obtained for the M1 sensor in the presence of $\mathrm{Mn}^{2+}$ ions (Figure S4), the effect of the polarity of the medium on the fluorescence of the sensor was lower. With these control experiments we can conclude that the 'turn-on' response for the M1 sensor observed in cells treated with $\mathrm{Mn}^{2+}$ salts can be majorly attributed to the increase in $\mathrm{Mn}$ levels.

We next treated the $\mathrm{Mn}^{2+}$ exposed cells with a cell permeable divalent metal ion chelator tetrakis-(2-pyridylmethyl)ethylene-diamine (TPEN). A decrease in intensity of the M1 sensor channel was observed upon TPEN treatment (Figure 1Aa, rightmost panel). Cells that had not been externally treated with $\mathrm{Mn}^{2+}$ also showed a visible decrease in intensity in the M1 sensor emission when treated with TPEN indicating that the sensor could detect labile $\mathrm{Mn}^{2+}$ ions under physiological conditions (Figure S7). Importantly, intensity analysis on confocal images of $\mathrm{Mn}^{2+}$ untreated cells and $\mathrm{Mn}^{2+}$ treated cells on selected regions of interest that showed co-localization of the M1 sensor channel with the Golgi tracker, showed a clear increase with increasing levels of $\mathrm{Mn}^{2+}$ exposure (Figure 1B). Further, TPEN treated cells showed lower intensity in the green channel (Figure 1B). The distinct increase in the emission intensity of the M1 sensor in regions marked with the Golgi tracker with increasing levels of $\mathrm{Mn}^{2+}$ exposure and decrease in intensity upon TPEN treatment demonstrate that the Golgi apparatus is involved in both channeling and 
storage of $\mathrm{Mn}^{2+}$ ions. Further, the presence of $\mathrm{Mn}^{2+}$ within the Golgi apparatus of cells that were not externally treated with $\mathrm{Mn}^{2+}$ as indicated by the co-localization of the fluorescence intensity of the M1 sensor in regions marked by the Golgi tracker (Figure 1A, leftmost panels) hints toward a possible role of the Golgi apparatus as an $\mathrm{Mn}^{2+}$ storage site under physiological conditions. This point can be confirmed in the future with the development second generation organelle targeted $\mathrm{Mn}^{2+}$ sensors with increased sensitivity. Finally, the fluorescence studies with the M1 sensor indicated that this chemical tool could be applied for studying $\mathrm{Mn}^{2+}$ regulation within the Golgi apparatus in the future. However, before applying any fluorescent sensor for elucidating mechanistic pathways it would be crucial to cross-validate the results obtained using an orthogonal imaging technique. We therefore chose nano-SXRF imaging as the technique to confirm the observations from our fluorescence microscopy results.

\section{Validating confocal fluorescence imaging results with nano-SXRF imaging}

Nano-SXRF imaging provides high resolution elemental maps with 30-300 nm spatial resolution. $^{40}$ This technique is based on the use of X-ray beams to eject core electrons from atoms and record the atomic X-ray fluorescence emission as electrons from higher energy levels fill in the hole generated in the core shell. SXRF can afford precise elemental maps thus providing a wealth of information on metal ion accumulation in frozen or freeze-dried cells. ${ }^{45}$ Nano-SXRF can detect the total metal pool in cells, which includes both metal ions tightly bound to biomolecules and the more labile and chelatable metal pool. Further, the development of protocols that can afford both epifluorescence microscopy and nano-SXRF imaging data on the same biological sample makes the technique applicable for determining organelle specific localization of metal ions. 

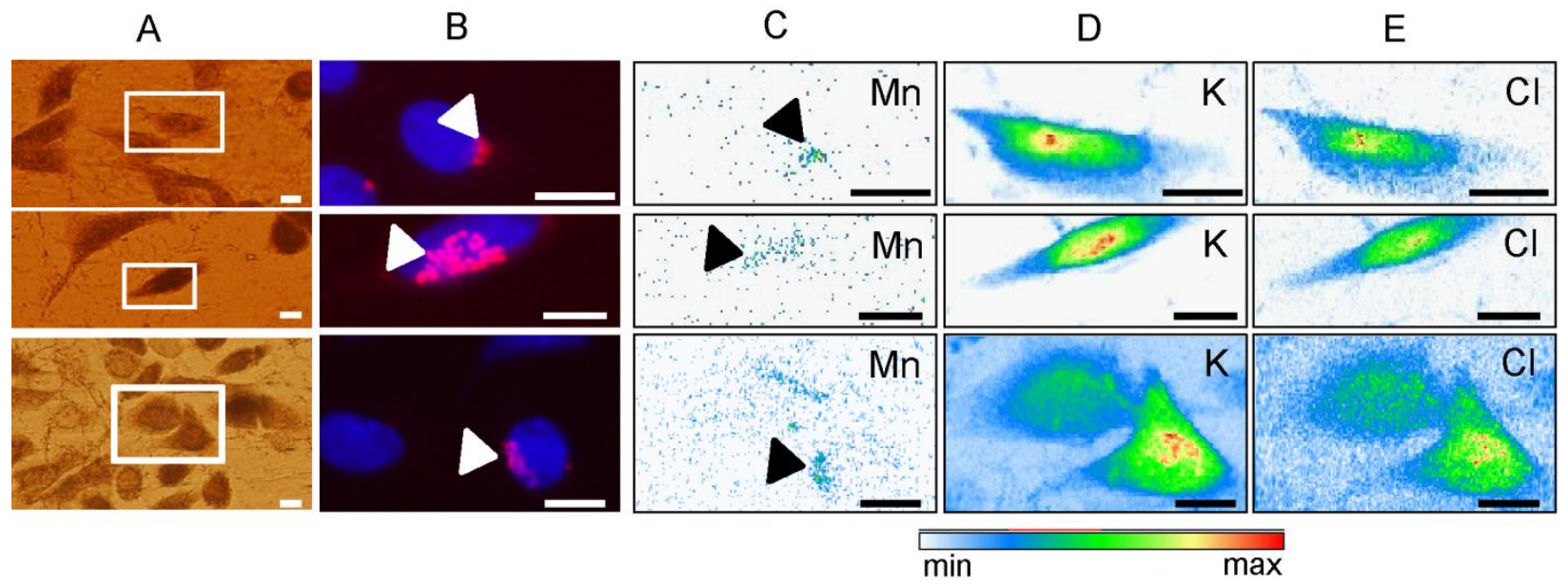

Figure 2. (A) Representative transmission images of HEK $293 \mathrm{~T}$ cells after cryo-fixation and freeze-drying. (B) Epifluorescence images of Golgi tracker (red) and nucleus staining (blue) before cryo-fixation. Not all cells incorporated the Golgi tracker. (C) Mn map in the cells indicated in (B), exposed to $25 \mu \mathrm{M} \mathrm{Mn}^{2+}$ generated by nano-SXRF imaging. (D) Potassium maps and (E) Chloride maps generated by nano-SXRF. $\mathrm{Mn}, \mathrm{K}$ and $\mathrm{Cl}$ distributions in cells are displayed with a color scale from minimum (white) to maximum (red) SXRF counts. Arrows indicate colocalization of Golgi and $\mathrm{Mn} . \mathrm{K}$ and $\mathrm{Cl}$ maps were used for obtaining the cellular outline. Scale bars: $10 \mu \mathrm{m}$.

In order to confirm whether $\mathrm{Mn}^{2+}$ ions indeed accumulate in the Golgi apparatus in HEK293T cells, as indicated by our confocal fluorescence microscopy experiments with the M1 sensor, we performed nano-SXRF imaging studies on the same cell line under identical $\mathrm{Mn}^{2+}$ exposure conditions. The cells were first transduced with the Golgi-RFP marker followed by exogenous $\mathrm{Mn}^{2+}$ treatment and incubation with a nucleus staining dye. The living cells were then imaged on an epifluorescence microscopy set-up and later freeze-dried for nano-SXRF imaging. The transmission images of the freeze-dried cells are depicted in Figures 2A and 4A and indicate that 
the cellular morphology was preserved after the sample preparation protocol. The Mn elemental maps generated on cells treated with $25 \mu \mathrm{M} \mathrm{Mn}{ }^{2+}$ salts indicated higher intensities in regions (Figure 2C) that co-localized with the Golgi stain in the epifluorescence image (Figure 2B). This result clearly confirmed our fluorescence microscopy observations and indicated that the Golgi apparatus could indeed accumulate $\mathrm{Mn}^{2+}$ ions in HEK293T cells. The pixel intensities in the Mn maps were low; however the Mn levels observed were close to the detection limit of XRF in a single pixel with $300 \mathrm{~ms}$ exposure time. The presence of $\mathrm{Mn}$ within the cells was also unambiguously concluded from the sum-spectra of the whole cells (Figure 3).

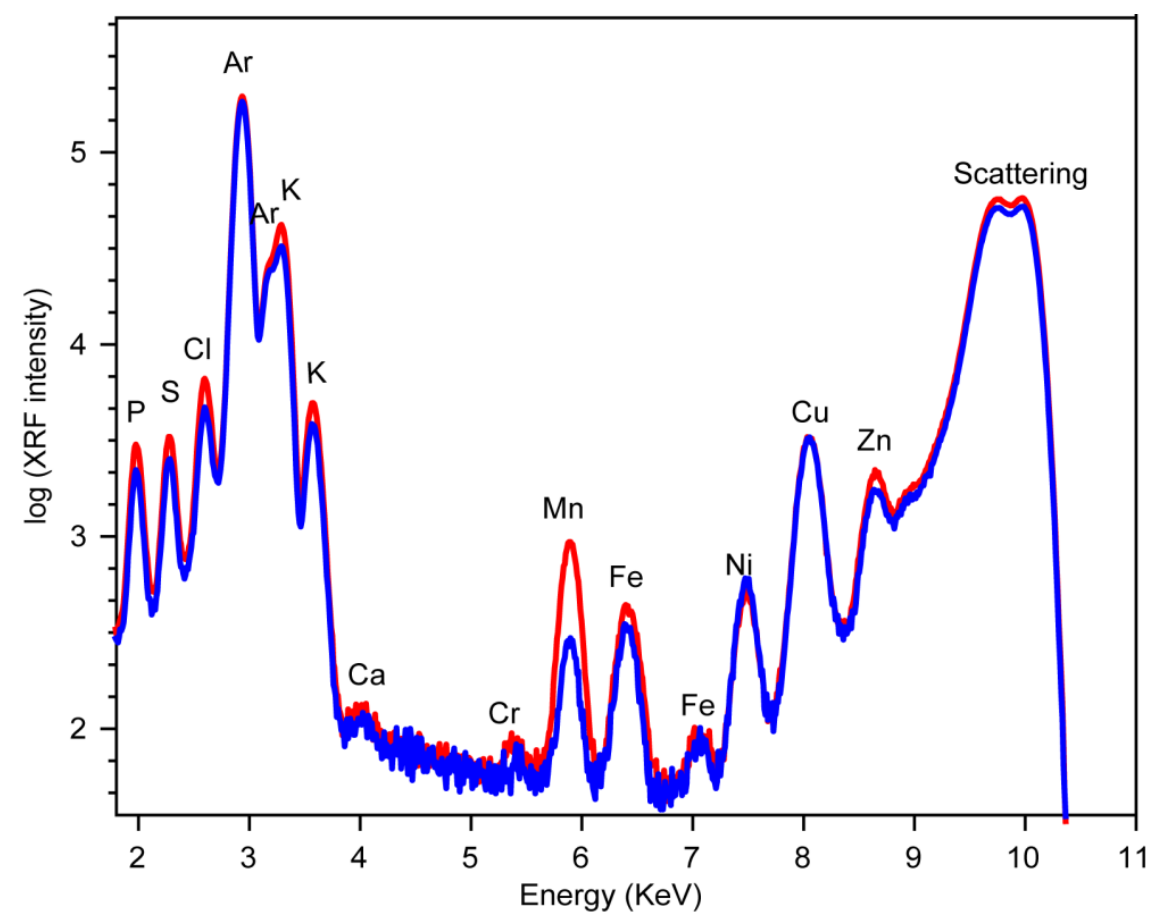

Figure 3. SXRF sum-spectra of single cells exposed to $25 \mu \mathrm{M} \mathrm{Mn}^{2+}$ (blue curve) and $250 \mu \mathrm{M}$ $\mathrm{Mn}^{2+}$ (red curve), after cryofixation and freeze drying. The spectra have been normalized by the scattered X-ray beam intensity and total exposure time to enable comparison of the analyses. 
A
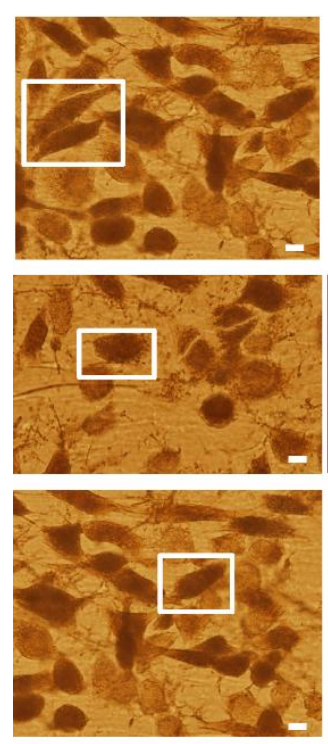

B
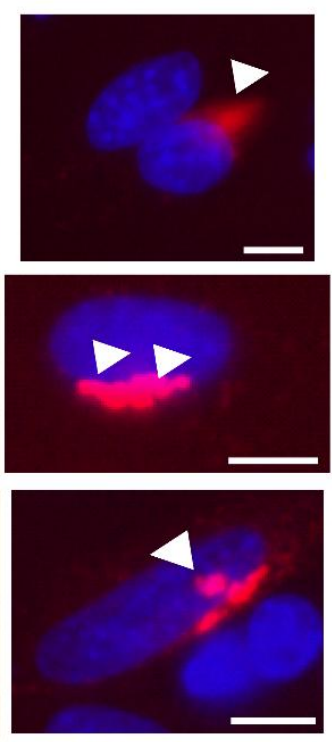
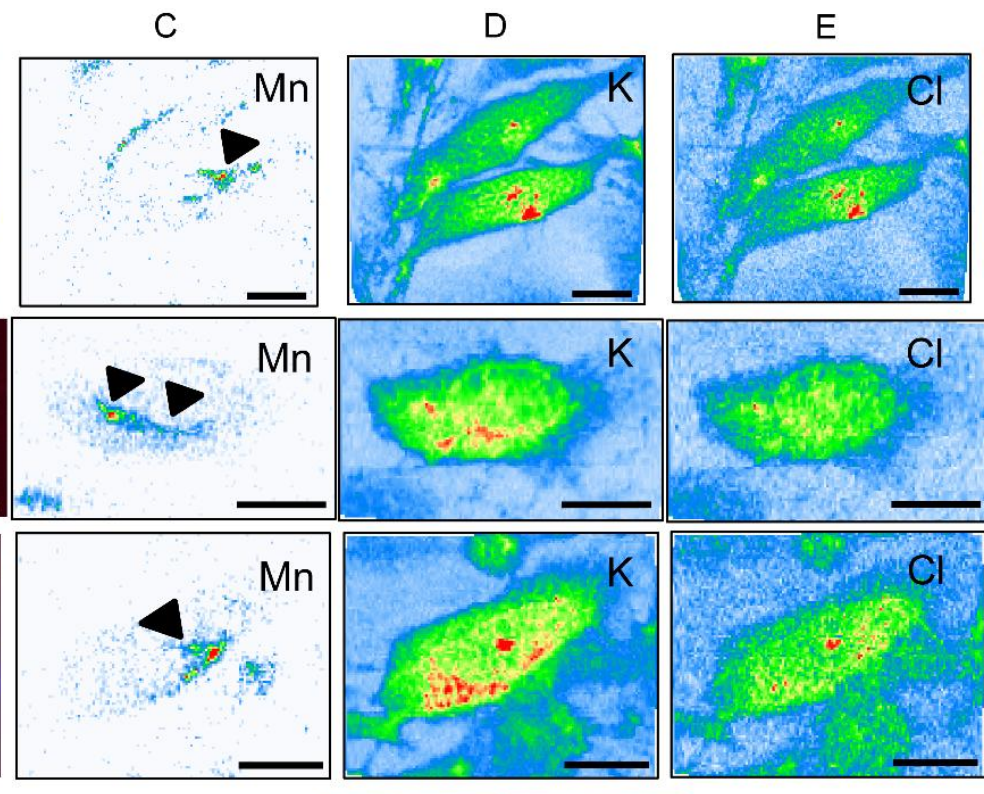
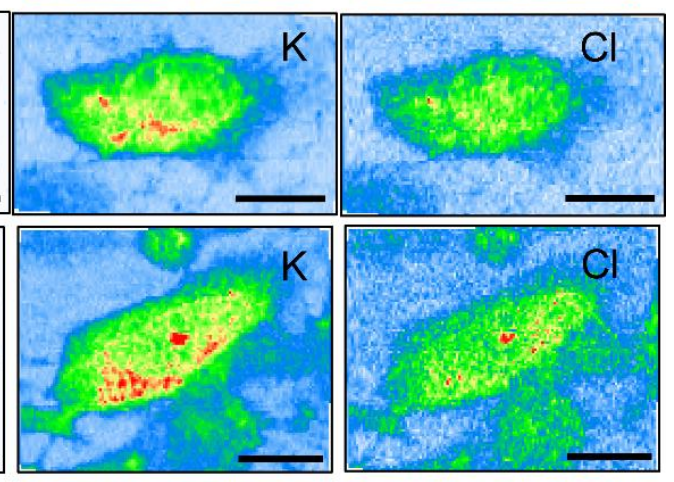

min

$\max$

Figure 4. (A) Representative transmission images of HEK $293 \mathrm{~T}$ cells after cryo-fixation and freeze-drying. (B) Epifluorescence images of Golgi tracker (red) and nucleus staining (blue) before cryo-fixation, not all cells incorporated the Golgi tracker. (C) Mn map in the cells indicated in (B), exposed to $250 \mu \mathrm{M} \mathrm{Mn}^{2+}$ generated by nano-SXRF imaging. (D) Potassium maps and (E) Chloride maps generated by nano-SXRF. $\mathrm{Mn}, \mathrm{K}$, and $\mathrm{Cl}$ distributions in cells are displayed with a color scale from minimum (white) to maximum (red) SXRF counts. Arrows indicate co-localization of Golgi and $\mathrm{Mn} . \mathrm{K}$ and $\mathrm{Cl}$ maps were used for obtaining the cellular outline. Scale bars: $10 \mu \mathrm{m}$.

Finally, to revalidate the observation that increased levels of external Mn exposure would lead to increased Mn levels in the Golgi apparatus as shown by our confocal imaging data, we analyzed the nano-SXRF experiments at $250 \mu \mathrm{M}$ external $\mathrm{Mn}^{2+}$ exposure level (Figure 4). Representative images of different cells are depicted in Figure 4 and clearly show Mn localization within the Golgi apparatus. Importantly, intensity analysis of the nano-SXRF images from representative samples of the two different sets of experiments $(25 \mu \mathrm{M}$ and $250 \mu \mathrm{M}$, respectively) clearly 
indicated an increase in only the overall cellular $\mathrm{Mn}$ levels with higher external $\mathrm{Mn}^{2+}$ exposure (Figure 3). Further, Mn exposure in these cells did not seem to affect the homeostasis of other essential elements and metal ions. Notably, this data distinctly cross-validated the results obtained with the M1 sensor indicating the central role of the Golgi apparatus in Mn storage.

\section{CONCLUSIONS AND PERSPECTIVES}

We have used a combination of information from confocal imaging studies using a sensitive 'turn-on' fluorescent $\mathrm{Mn}^{2+}$ sensor and nano-SXRF imaging on cells exposed to sub-cytotoxic levels of $\mathrm{Mn}$ to elucidate intra-cellular $\mathrm{Mn}$ localization. The $\mathrm{Mn}^{2+}$ sensor showed fluorescence emission within the Golgi apparatus of HEK293T cells under physiological conditions in the absence of any external Mn exposure. Importantly, the 'turn-on' sensor was able to reveal an increased accumulation of $\mathrm{Mn}^{2+}$ ions in the Golgi apparatus with increasing levels of $\mathrm{Mn}^{2+}$ exposure. The confocal microscopy results with the fluorescent sensor indicated a distinct role of the Golgi apparatus as an $\mathrm{Mn}^{2+}$ storage site under sub-cytotoxic Mn exposure conditions and also hinted toward a possible role of the Golgi apparatus in Mn storage under physiological conditions. The results obtained from confocal microscopy were distinctly confirmed by nanoSXRF, a chemical element imaging technique sensitive to total cellular Mn content. With the experiments on the HEK293T cells in addition to previous studies in HeLa and other neuronal cell lines, the Golgi apparatus can now be established as a compartment that is used for Mn storage and channeling under sub-cytotoxic Mn levels. These experiments have also afforded crucial validation of the $\mathrm{Mn}^{2+}$ sensing ability of the M1 sensor in living cells. Further, in the future, the capacity of the M1 sensor to detect $\mathrm{Mn}^{2+}$ in the Golgi apparatus will open possibilities for quantification of $\mathrm{Mn}$ levels by using a combination of second generation ratiometric fluorescent sensors with attractive elemental mapping techniques like nano-SXRF. Finally, our 
research approach provides a pilot-study on how existing fluorescent sensors can be strategically combined with different validation techniques and protocols to elucidate metal-ion compartmentalization and dynamics.

\section{AUTHOR INFORMATION}

\section{Corresponding Author}

* Email: ankona@tifr.res.in (AD)

\section{Author Contributions}

The manuscript was written through contributions of all authors. All authors have reviewed and given approval to the final version of the manuscript.

†These authors contributed equally.

\section{ACKNOWLEDGMENT}

AD acknowledges TIFR and Department of Atomic Energy, India for supporting the research on the development of $\mathrm{Mn}^{2+}$ selective fluorescent sensors and for travel support to perform experiments at the SOLEIL synchrotron. The authors acknowledge SOLEIL for the provision of synchrotron radiation facilities and for assistance in using beamline "NANOSCOPIUM" and Dr. Kadda Medjoubi for help with SXRF data processing. The authors acknowledge Dr. Dayana Surendran for plating cells and Dr. Manasi Damodar Talwadekar for providing cells and the Lyso and Mito Trackers. AD is grateful to Dr. Somshuvra Mukhopadhyay for helpful discussions on the SLC30A10 transporter expression levels in HEK293T cells. RO is acknowledges CNRS/IN2P3, master project IFI, France, for funding the project part on metal imaging using synchrotron radiation techniques.

SUPPORTING INFORMATION AVAILABLE 
Details of experimental protocols, co-localization data with organelle trackers, and in vitro control experiments with the fluorescent $\mathrm{Mn}^{2+}$ sensor.

\section{REFERENCES}

1. Hong-Hermesdorf, A.; Miethke, M.; Gallaher, S. D.; Kropat, J.; Dodani, S. C.; Chan, J.; Barupala, D.; Domaille, D. W.; Shirasaki, D. I.; Loo, J. A.; Weber, P. K.; Pett-Ridge, J.; Stemmler, T. L.; Chang, C. J.; Merchant, S. S., Subcellular metal imaging identifies dynamic sites of $\mathrm{Cu}$ accumulation in Chlamydomonas. Nat. Chem. Biol. 2014, 10 (12), 1034-42.

2. Chang, C. J., Bioinorganic Life and Neural Activity: Toward a Chemistry of Consciousness? Acc. Chem. Res 2017, 50 (3), 535-538.

3. Que, E. L.; Bleher, R.; Duncan, F. E.; Kong, B. Y.; Gleber, S. C.; Vogt, S.; Chen, S.; Garwin, S. A.; Bayer, A. R.; Dravid, V. P.; Woodruff, T. K.; O'Halloran, T. V., Quantitative mapping of zinc fluxes in the mammalian egg reveals the origin of fertilization-induced zinc sparks. Nat. Chem. 2014, 7, 130.

4. Waldron, K. J.; Robinson, N. J., How do bacterial cells ensure that metalloproteins get the correct metal? Nat. Rev. Microbiol. 2009, 7 (1), 25-35.

5. Mukhopadhyay, S.; Linstedt, A. D., Manganese Blocks Intracellular Trafficking of Shiga Toxin and Protects Against Shiga Toxicosis. Science 2012, 335 (6066), 332.

6. Mukhopadhyay, S.; Redler, B.; Linstedt, A. D., Shiga toxin-binding site for host cell receptor GPP130 reveals unexpected divergence in toxin-trafficking mechanisms. Mol. Biol. Cell 2013, 24 (15), 2311-2318.

7. Brophy, M. B.; Nolan, E. M., Manganese and microbial pathogenesis: sequestration by the Mammalian immune system and utilization by microorganisms. ACS Chem. Biol. 2015, 10 (3), $641-51$. 
8. Zygiel, E. M.; Nolan, E. M., Transition Metal Sequestration by the Host-Defense Protein Calprotectin. Annu. Rev. Biochem. 2018, 87 (1), 621-643.

9. Barnese, K.; Gralla, E. B.; Cabelli, D. E.; Selverstone Valentine, J., Manganous Phosphate Acts as a Superoxide Dismutase. J. Am. Chem. Soc. 2008, 130 (14), 4604-4606.

10. Dodani, S. C.; Firl, A.; Chan, J.; Nam, C. I.; Aron, A. T.; Onak, C. S.; Ramos-Torres, K. M.; Paek, J.; Webster, C. M.; Feller, M. B.; Chang, C. J., Copper is an endogenous modulator of neural circuit spontaneous activity. Proc. Natl. Acad. Sci. 2014, 111 (46), 16280.

11. Carter, K. P.; Young, A. M.; Palmer, A. E., Fluorescent Sensors for Measuring Metal Ions in Living Systems. Chem. Rev. 2014, 114 (8), 4564-4601.

12. Que, E. L.; Domaille, D. W.; Chang, C. J., Metals in neurobiology: probing their chemistry and biology with molecular imaging. Chem. Rev. 2008, 108 (5), 1517-49.

13. Cotruvo, J. J. A.; Aron, A. T.; Ramos-Torres, K. M.; Chang, C. J., Synthetic fluorescent probes for studying copper in biological systems. Chem. Soc. Rev. 2015, 44 (13), 4400-4414.

14. Das, S.; Khatua, K.; Rakshit, A.; Carmona, A.; Sarkar, A.; Bakthavatsalam, S.; Ortega, R.; Datta, A., Emerging chemical tools and techniques for tracking biological manganese. Dalton Trans. 2019.

15. da Cunha, M. M. L.; Trepout, S.; Messaoudi, C.; Wu, T.-D.; Ortega, R.; Guerquin-Kern, J.-L.; Marco, S., Overview of chemical imaging methods to address biological questions. Micron 2016, $84,23-36$.

16. Daly, M. J.; Gaidamakova, E. K.; Matrosova, V. Y.; Vasilenko, A.; Zhai, M.; Venkateswaran, A.; Hess, M.; Omelchenko, M. V.; Kostandarithes, H. M.; Makarova, K. S.; Wackett, L. P.; Fredrickson, J. K.; Ghosal, D., Accumulation of Mn(II) in Deinococcus radiodurans facilitates gamma-radiation resistance. Science 2004, 306 (5698), 1025-8. 
17. McNaughton, R. L.; Reddi, A. R.; Clement, M. H. S.; Sharma, A.; Barnese, K.; Rosenfeld, L.; Gralla, E. B.; Valentine, J. S.; Culotta, V. C.; Hoffman, B. M., Probing in vivo $\mathrm{Mn}^{2+}$ speciation and oxidative stress resistance in yeast cells with electron-nuclear double resonance spectroscopy. Proc. Natl. Acad. Sci. 2010, 107 (35), 15335.

18. Sharma, A.; Gaidamakova, E. K.; Matrosova, V. Y.; Bennett, B.; Daly, M. J.; Hoffman, B. M., Responses of Mn2+ speciation in Deinococcus radiodurans and Escherichia coli to gammaradiation by advanced paramagnetic resonance methods. Proc. Natl. Acad. Sci. U. S. A. 2013, $110(15), 5945-50$.

19. Tuschl, K.; Meyer, E.; Valdivia, L. E.; Zhao, N.; Dadswell, C.; Abdul-Sada, A.; Hung, C. Y.; Simpson, M. A.; Chong, W. K.; Jacques, T. S.; Woltjer, R. L.; Eaton, S.; Gregory, A.; Sanford, L.; Kara, E.; Houlden, H.; Cuno, S. M.; Prokisch, H.; Valletta, L.; Tiranti, V.; Younis, R.; Maher, E. R.; Spencer, J.; Straatman-Iwanowska, A.; Gissen, P.; Selim, L. A.; Pintos-Morell, G.; Coroleu-Lletget, W.; Mohammad, S. S.; Yoganathan, S.; Dale, R. C.; Thomas, M.; Rihel, J.; Bodamer, O. A.; Enns, C. A.; Hayflick, S. J.; Clayton, P. T.; Mills, P. B.; Kurian, M. A.; Wilson, S. W., Mutations in SLC39A14 disrupt manganese homeostasis and cause childhood-onset parkinsonism-dystonia. Nat. Commun. 2016, 7, 11601.

20. Sharma, A.; Gaidamakova, E. K.; Grichenko, O.; Matrosova, V. Y.; Hoeke, V.; Klimenkova, P.; Conze, I. H.; Volpe, R. P.; Tkavc, R.; Gostinčar, C.; Gunde-Cimerman, N.; DiRuggiero, J.; Shuryak, I.; Ozarowski, A.; Hoffman, B. M.; Daly, M. J., Across the tree of life, radiation resistance is governed by antioxidant $\mathrm{Mn}^{2+}$, gauged by paramagnetic resonance. Proc. Natl. Acad. Sci. U. S. A. 2017, 114 (44), E9253.

21. Barnese, K.; Gralla, E. B.; Valentine, J. S.; Cabelli, D. E., Biologically relevant mechanism for catalytic superoxide removal by simple manganese compounds. Proc. Natl. Acad. Sci. U. S. A. 2012, 109 (18), 6892-7. 
22. Tuschl, K.; Clayton, P. T.; Gospe, S. M., Jr.; Gulab, S.; Ibrahim, S.; Singhi, P.; Aulakh, R.; Ribeiro, R. T.; Barsottini, O. G.; Zaki, M. S.; Del Rosario, M. L.; Dyack, S.; Price, V.; Rideout, A.; Gordon, K.; Wevers, R. A.; Chong, W. K.; Mills, P. B., Syndrome of hepatic cirrhosis, dystonia, polycythemia, and hypermanganesemia caused by mutations in SLC30A10, a manganese transporter in man. Am. J. Hum. Genet. 2012, 90 (3), 457-66.

23. Jenkitkasemwong, S.; Wang, C.-Y.; Mackenzie, B.; Knutson, M. D. J. B., Physiologic implications of metal-ion transport by ZIP14 and ZIP8. Biometals. 2012, 25 (4), 643-655.

24. Park, J. H.; Hogrebe, M.; Gruneberg, M.; DuChesne, I.; von der Heiden, A. L.; Reunert, J.; Schlingmann, K. P.; Boycott, K. M.; Beaulieu, C. L.; Mhanni, A. A.; Innes, A. M.; Hortnagel, K.; Biskup, S.; Gleixner, E. M.; Kurlemann, G.; Fiedler, B.; Omran, H.; Rutsch, F.; Wada, Y.; Tsiakas, K.; Santer, R.; Nebert, D. W.; Rust, S.; Marquardt, T., SLC39A8 Deficiency: A Disorder of Manganese Transport and Glycosylation. Am. J. Hum. Genet. 2015, 97 (6), 894-903.

25. Xin, Y.; Gao, H.; Wang, J.; Qiang, Y.; Imam, M. U.; Li, Y.; Wang, J.; Zhang, R.; Zhang, H.; Yu, Y.; Wang, H.; Luo, H.; Shi, C.; Xu, Y.; Hojyo, S.; Fukada, T.; Min, J.; Wang, F., Manganese transporter Slc39a14 deficiency revealed its key role in maintaining manganese homeostasis in mice. Cell Discov. 2017, 3, 17025.

26. Saudubray, J.-M.; Garcia-Cazorla, A., An overview of inborn errors of metabolism affecting the brain: from neurodevelopment to neurodegenerative disorders. Dialogues Clin. Neurosci. 2018, 20 (4), 301-325.

27. Stamelou, M.; Tuschl, K.; Chong, W. K.; Burroughs, A. K.; Mills, P. B.; Bhatia, K. P.; Clayton, P. T., Dystonia with brain manganese accumulation resulting from SLC30A10 mutations: a new treatable disorder. Mov. Disord. 2012, 27 (10), 1317-22. 
28. Mukhtiar, K.; Ibrahim, S.; Tuschl, K.; Mills, P., Hypermanganesemia with Dystonia, Polycythemia and Cirrhosis (HMDPC) due to mutation in the SLC30A10 gene. Brain Dev. 2016, 38 (9), 862-5.

29. Mukhopadhyay, S., Familial manganese-induced neurotoxicity due to mutations in SLC30A10 or SLC39A14. NeuroToxicology 2018, 64, 278-283.

30. Mukhopadhyay, S.; Linstedt, A. D., Identification of a gain-of-function mutation in a Golgi P-type ATPase that enhances Mn2+ efflux and protects against toxicity. Proc. Natl. Acad. Sci. U.

S. A. 2011, 108 (2), 858-63.

31. Sengupta, D.; Linstedt, A. D., Control of organelle size: the Golgi complex. Annu. Rev. Cell Dev. Biol. 2011, 27, 57-77.

32. Carmona, A.; Devès, G.; Roudeau, S.; Cloetens, P.; Bohic, S.; Ortega, R., Manganese Accumulates within Golgi Apparatus in Dopaminergic Cells as Revealed by Synchrotron X-ray Fluorescence Nanoimaging. ACS Chem. Neurosci. 2010, 1 (3), 194-203.

33. Ortega, R.; Carmona, A., Golgi apparatus functions in manganese homeostasis and detoxification. In Golgi apparatus: structure, functions and mechanisms. Nova Science Publishers, Inc., New York: 2011; p 151-160.

34. Roudeau, S.; Carmona, A.; Perrin, L.; Ortega, R., Correlative organelle fluorescence microscopy and synchrotron X-ray chemical element imaging in single cells. Anal. Bioanal. Chem. 2014, 406 (27), 6979-91.

35. Carmona, A.; Zogzas, C. E.; Roudeau, S.; Porcaro, F.; Garrevoet, J.; Spiers, K. M.; Salomé, M.; Cloetens, P.; Mukhopadhyay, S.; Ortega, R., SLC30A10 Mutation Involved in Parkinsonism Results in Manganese Accumulation within Nanovesicles of the Golgi Apparatus. ACS Chem. Neurosci. 2019, 10 (1), 599-609. 
36. Leyva-Illades, D.; Chen, P.; Zogzas, C. E.; Hutchens, S.; Mercado, J. M.; Swaim, C. D.; Morrisett, R. A.; Bowman, A. B.; Aschner, M.; Mukhopadhyay, S., SLC30A10 Is a Cell Surface-Localized Manganese Efflux Transporter, and Parkinsonism-Causing Mutations Block Its Intracellular Trafficking and Efflux Activity. J. Neurosci. 2014, 34 (42), 14079.

37. Bakthavatsalam, S.; Sarkar, A.; Rakshit, A.; Jain, S.; Kumar, A.; Datta, A., Tuning macrocycles to design 'turn-on' fluorescence probes for manganese(ii) sensing in live cells. Chem. Commun. 2015, 51 (13), 2605-2608.

38. https://assets.thermofisher.com/TFS-Assets/LSG/manuals/CellLight_Reagents_QRC.pdf [Accessed 17 Jul, 2019].

39. Perrin, L.; Carmona, A.; Roudeau, S.; Ortega, R., Evaluation of sample preparation methods for single cell quantitative elemental imaging using proton or synchrotron radiation focused beams. J. Anal. At. Spectrom. 2015, 30 (12), 2525-2532.

40. Somogyi, A.; Medjoubi, K.; Baranton, G.; Le Roux, V.; Ribbens, M.; Polack, F.; Philippot, P.; Samama, J.-P., Optical design and multi-length-scale scanning spectro-microscopy possibilities at the Nanoscopium beamline of Synchrotron Soleil. J. Synchrotron Rad. 2015, 22 (4), 1118-1129.

41. Hostachy, S.; Masuda, M.; Miki, T.; Hamachi, I.; Sagan, S.; Lequin, O.; Medjoubi, K.; Somogyi, A.; Delsuc, N.; Policar, C., Graftable SCoMPIs enable the labeling and X-ray fluorescence imaging of proteins. Chem. Sci. 2018, 9 (19), 4483-4487.

42. Medjoubi, K.; Leclercq, N.; Langlois, F.; Buteau, A.; Le, S.; Poirier, S.; Mercere, P.; Sforna, M. C.; Kewish, C. M.; Somogyi, A., Development of fast, simultaneous and multitechnique scanning hard X-ray microscopy at Synchrotron Soleil. J. Synchrotron Rad. 2013, 20 (2), 293-299. 
43. Khan, M.; Goldsmith, C. R.; Huang, Z.; Georgiou, J.; Luyben, T. T.; Roder, J. C.; Lippard, S. J.; Okamoto, K., Two-photon imaging of Zn2+ dynamics in mossy fiber boutons of adult hippocampal slices. Proc. Natl. Acad. Sci. U.S.A. 2014, 111 (18), 6786-6791.

44. Llopis, J.; McCaffery, J. M.; Miyawaki, A.; Farquhar, M. G.; Tsien, R. Y., Measurement of cytosolic, mitochondrial, and Golgi $\mathrm{pH}$ in single living cells with green fluorescent proteins. Proc. Natl. Acad. Sci. 1998, 95 (12), 6803.

45. Zhang, R.; Li, L.; Sultanbawa, Y.; Xu, Z. P., X-ray fluorescence imaging of metals and metalloids in biological systems. Am. J. Nucl. Med. Mol. Imaging 2018, 8 (3), 169-188.

TOC

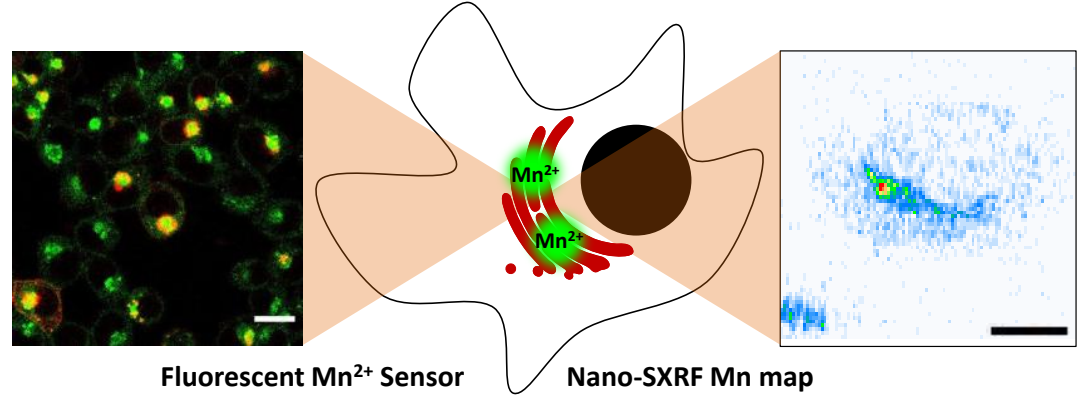

\section{TOC SYNOPSIS}

Combination of confocal fluorescence imaging using a 'turn-on' fluorescent $\mathrm{Mn}^{2+}$ sensor and $\mathrm{Mn}$ elemental maps generated by nano synchrotron X-ray fluorescence imaging reveal $\mathrm{Mn}$ localization within Golgi apparatus under both physiological and sub-cytotoxic Mn exposure conditions. 